\title{
TRADICIÓN LEGENDARIA DURANTE EL AUGE DEL CINE GALLEGO DE ANIMACIÓN: TRES APROXIMACIONES NARRATIVAS
}

\author{
David Fuentefría Rodríguez \\ Universidad de La Laguna
}

\section{RESUMEN}

Galicia es, sin duda, uno de los enclaves con más y mejor tradición legendaria de toda Europa. Es bien sabido, igualmente, que, desde los años 90 y hasta unos años después de la crisis de 2008, la animación producida en esta comunidad experimentó un auge parejo tan solo a los problemas sufridos a posteriori por sus estudios de producción, lo que no impidió, por otro lado, que los trazos más elementales de la mitología de esta tierra se exportasen, a través de las modernas formas y argumentos de las películas de dibujos, en ocasiones con amplia repercusión dentro y fuera de nuestras fronteras. Este artículo estudia tres de los filmes de la última etapa del fenómeno, ahondando en sus fuentes mitológicas y, sobre todo, en la traslación de su ancestral poética a las narrativas audiovisuales vigentes: se trata de De profundis (Miguelanxo Prado, 2006), El apóstol (Fernando Cortizo, 2012) y Brujerías (Virginia Curiá/Tomás Conde, 2013).

Palabras Clave: tradición, leyendas, cine, animación, Galicia.

\section{LEGENDARY TRADITION DURING THE HEIGHT OF GALICIAN ANIMATED CINEMA: THREE NARRATIVE APPROACHES}

\section{Abstract}

Galicia is, without a doubt, one of the Europe's places with more and better legendary tradition. It's well known, also, that, since the 90s of the last century, and until a few years after the 2008's crisis, the animation produced in this community experienced a boom only similar to the problems suffered afterwards, by their studios, which did not prevent that the most elementary traces of mythology and legends of this land were exported, through the modern forms and arguments of the animated movies, sometimes with wide repercussion within and outside our borders. This article studies three of the films of the last stage of the phenomenon, delving into its mythological sources and, above all, in the translation of its ancestral poetics to current audiovisual narratives: "De profundis" (Miguelanxo Prado, 2006), "El apóstol” (Fernando Cortizo, 2012), and "Brujerías" (Virginia Curiá / Tomás Conde, 2013).

KEYwORDs: tradition, legends, movies, animation, Galicia. 


\section{INTRODUCCIÓN}

En coincidencia con un fenómeno similar en el País Vasco, la flamante aunque efímera carrera del cine de animación producido en Galicia encuentra sus inicios en la década de los 90, momento en que la Xunta empieza a considerar al audiovisual como un sector estratégico para su comunidad, con especial énfasis en un género que, en principio, pocos habrían considerado puntal para tales menesteres: las películas de animación. Es cierto que, merced a las primeras ayudas específicas, surgieron tres largometrajes pioneros, todos producidos en 1989 y ninguno de dibujos animados: Urxa (Alfredo García Pinal/Carlos López Piñeiro), Siempre Xonxa (Chano Piñeiro) y Continental (Xavier Villaverde), cosechando la segunda un gran éxito en Galicia, y compitiendo con la primera en cuanto a impregnación de material extraído de los mitos y leyendas de esta comunidad.

No es menos cierto que estos filmes siguieron la estela de algunos clásicos enraizados en la memoria nacional, como El bosque del lobo (Ped ro Olea, 1971), inspirada en el «licántropo» orensano Manuel Gómez Romasanta; El bosque animado (José Luis Cuerda, 1987), sobre la obra homónima del ilustre corunés Wenceslao Fernández Flórez, o Divinas palabras (1987), en la que José Luis García Sánchez trasladaba a la Galicia de los años 20 la muy conocida comedia bárbara, anterior al esperpento, de Ramón María del Valle-Inclán. Y si bien, a posteriori, nuestra cinematografía continuó abordando la prácticamente inabarcable tradición legendaria gallega (a veces con mixturas extrañas, en las que las tierras del norte servían solo como tablero reconocible sobre el que desplegar otro tipo de imaginerías, como en Dagon. La secta del mar, Stuart Gordon, 2001), es preciso dejar claro que dicha tradición es rastreable desde bien pronto, con películas como Alalá (los nietos de los celtas), dirigida en 1933 por el alemán Adolf Trotz, y en la que, en localizaciones de Pontevedra, Rianxo y Vigo, ya aparecía, sin ir más lejos, una meiga que aconsejaba al protagonista.

Pues bien, en orden a acotar tan amplio campo de estudio, y por la importancia del período citado, consideraremos la investigación del cine de animación repasando, primero, el proceso que condujo en esos años al auge de los estudios y las producciones localizadas en Galicia. Citaremos, después, sus principales baluartes, y examinaremos, tras una breve composición de lugar previa en torno a la mitología legendaria gallega, tres de las propuestas más atractivas, y a la vez diferentes entre sí, de los últimos años de la etapa: De profundis (Miguelanxo Prado, 2006), El apóstol (Fernando Cortizo, 2012), y Brujerías (Virginia Curiá/Tomás Conde, 2013). En todas, como se verá, se realizó un esfuerzo retórico especial por garantizar la pervivencia de toda la tradición secular de Galicia en torno a leyendas, criaturas mágicas y aspectos fantásticos. 


\section{LA ANIMACIÓN GALLEGA}

- ¡Ese hueso te sobra! -afirmó el componedor.

- ¿Cómo va a sobrarme un hueso? -se admiraba Bouso.

- Será el hueso del azogue, Bousiño. ¡Ese hueso les sobra a todos los que lo tienen! Y Primo, en un cedazo pequeńo, cernió tabaco de picadura mezclado con el de los pitillos que llamaban mataquintos, y le hizo sorber el rapé a Bouso. Le vinieron a éste unos estornudos fuertes, muy de arriba, y al tercero salió el hueso; parecía de ala de pollo, muy limpio, blanquito.

- ¡Parece que no es un hueso de hombre! -comentó Bouso.

- ¡Por eso te sobra!

La cabeza de Bouso (Álvaro Cunqueiro)

Uno de los nombres clave del grupo de pioneros que elevó la animación galaica a cuotas de calidad hasta entonces desconocidas es, sin duda, el de Manuel Gómez, quien creó la productora Dygra con el objetivo de hacer una película basada en las entonces novedosas técnicas de infografía, influido, entre otras referencias, por el cambio de paradigma que implicó, mundialmente, el advenimiento de Toy Story (John Lasseter, 1995). El resultado fue El bosque animado (2001), gestada desde 1996 y dirigida al alimón con Ángel de la Cruz, que cosechó un importante éxito comercial, y a la que siguieron dos cintas más: El sueño de una noche de San Juan (2005) y El espiritu del bosque (2008), secuela de El bosque animado.

Pero con el éxito llegaron también los problemas: la ampliación de Dygra que trajo consigo la excelente recepción de El bosque promovió la formación constante de nuevos animadores que, ante las restricciones que les imponía el trabajo dentro del marco de la comunidad gallega, terminaban, con el tiempo, marchándose acuciados por el estrés, o viajando a Madrid, en busca de mejores remuneraciones y continuidad laboral. Desde el momento en que las siguientes películas del equipo no obtuvieron el mismo aplauso que su buque insignia, la productora colapsó.

Pero, pese a este devenir, y a la fundamental aportación de Dygra, ésta fue solo uno de los pilares de la animación hecha en Galicia. Un segundo fue Continental (del productor Pancho Casas, y derivado a partir de la película antedicha), compañía recordada por filmes de estimable factura y aliento transgresor, como La crisis carnivora (Pedro Rivero, 2008), entre otros trabajos vanguardistas. Con todo, el tercer pilar, y sin duda el más importante, fue la internacionalmente conocida distribuidora Filmax, propiedad de Carlos y Julio Fernández, que durante esta época auspició la creación de los estudios Brent Entertainment, con trabajadores fijos, y responsable de Pérez, el ratoncito de tus sueños (Juan Pablo Buscarini, 2006), uno de los mayores éxitos de la animación española.

Como decíamos, fue la crisis económica de 2008 la que terminaría de dar la puntilla al efímero dominio nacional de la animación gallega. Salvo Pérez, el resto de las películas citadas no había recaudado grandes ingresos en taquilla, durante la época de "vacas gordas», con lo que, por los recortes en las subvenciones que acarreó el nuevo panorama económico, en los años siguientes, toda la estructura terminó, finalmente, por venirse abajo. Ello pese a la muy respetable calidad artística 
de productos como Donkey Xote (José Pozo, 2007), o las galardonadas El Cid, la leyenda (José Pozo, 2003) y Nocturna (Víctor Maldonado y Adriá García, 2008), que no podíamos dejar de mencionar.

Los que vivieron el fenómeno en primera persona relatan, además, que a todos estos problemas se une el hecho de que, en Galicia, las iniciativas respecto al tipo de cine que debía hacerse fueron siempre, en buena medida, producto de decisiones personales, y no de un trabajo de equipo fuertemente estructurado. Todavía hoy subsisten, para colmo, los problemas de antaño: el natural que puede presuponerse, dada la limitación del territorio, y la inveterada falta de formación de animadores.

Igualmente, y tras los primeros efectos de la crisis, se produjo algún fallo clamoroso en la distribución de algunos filmes que merece la pena señalar, como en el caso de El apóstol, precisamente uno de los que nos va a ocupar. El apóstol es una película con música del reputado Phillip Glass, y con un excelente equipo de directores de animación extranjeros, que, en teoría, podría y debería haber devuelto su esplendor reciente a la industria de la animación, pero que apenas llegó a estrenarse en 13 salas de toda España. A ello tampoco ayudó, según algunas voces, su tratamiento de una leyenda tan gallega como la de la Santa Compaña, conocida por casi todos pero difícil de entender, en todos sus matices, fuera de esta comunidad.

Cabe resaltar, por otra parte, el dato de que, con la crisis, el volumen de subvenciones para el audiovisual pasó progresivamente de siete a dos millones de euros, cantidad que, pese a cubrir otros quehaceres relacionados con el sector, incluidos los más de 35 festivales de cine que alberga en la actualidad esta autonomía, resulta a todas luces insuficiente para que un fenómeno como el descrito pueda repetirse, al menos a medio plazo.

A modo de curiosidad, y para finalizar, podemos indicar que buena parte de las películas mencionadas introducían elementos fantásticos o mágicos en sus argumentos (El bosque animado se adentra en el segmento de "La Fraga de Cecebre», de la obra homónima de Fernández Flórez, y en ella los árboles tienen una vida independiente a la de los humanos; El sueño de una noche de San Juan adapta la obra de Shakespeare a través de su protagonista, Elena, que no cree en las leyendas, aunque después inicia un viaje por el mundo de la magia; El pequeño mago -Roque Cameselle, 2013-insiste sobre las habilidades sobrenaturales del pequeño Bieito). $\mathrm{E}$ incluso las que no insistieron en este particular, como Arrugas (Ignacio Ferreras, 2001), que abordaba las cuitas de la ancianidad a través de dos amigos que comparten estancia en el asilo, o Copito de Nieve (Andrés G. Schaer, 2011), que mezcló imagen real y animaciones 3D, perviven en el inventario de esta época de expansión y esperanza para la animación gallega, por sus originales aportaciones o sus indudables riesgos técnicos ${ }^{1}$.

${ }^{1}$ Los medios de comunicación no dudaban, durante los momentos de mayor esplendor del período, en hablar de liderazgo absoluto, no solo en el cine de animación, sino en el cine español. Una muestra, de El Correo Gallego: http://www.elcorreogallego.es/tema-del-dia/ecg/animacion-gallega-reafirma-su-liderazgo-cine-espanol/idEdicion-2007-01-30/idNoticia-129401/. 


\section{GALICIA: TRADICIÓN, LEYENDA \\ E IDIOSINCRASIA}

Una noche, noche negra

como el pesar que yo tengo,

noche hija de las sombrías

alas que extienden los miedos;

hora en que cantan los gallos,

hora en que gimen los vientos, y las meigas bailan, bailan

con el demonio primero,

arrancando verdes robles,

puertas y tejas hendiendo,

todas de blanco vestidas,

sueltos los blancos cabellos,

contra las que el can aúlla

augurando triste entierro (...).

\section{Cantares gallegos (Rosalía de Castro)}

Quienes allá viven lo saben, y lo reconocen abiertamente: es casi imposible dar un paso en Galicia, en el terreno artístico, patrimonial o educativo, sin que, directa o indirectamente, surja la influencia de los cuentos y leyendas de su inmensa cultura popular, relacionada mayoritariamente con pueblos y aldeas, donde hallan su principal raíz.

Esta riqueza en las tradiciones se debe principalmente a un fenómeno geográfico, de la propia ubicación de la comunidad galaica, en la esquina del país, que provocó que casi todos los grandes movimientos estéticos, artísticos y culturales, como el Romanticismo, se incorporaran necesariamente más tarde a sus territorios. No se trata de un fenómeno aislado; de hecho, Bretaña y Gales, enclaves igualmente de pasado celta, y situados geográficamente, también, en sus respectivas esquinas del mapa, comparten una idiosincrasia parecida. Por Galicia no pasaron tampoco, en su momento, ni la Ilustración ni la Revolución Francesa, y, como dato curioso, no es un secreto que, en el año 1954, los catedráticos todavía negaban la Teoría de la Evolución en las universidades gallegas.

Distintos son, por otro lado, los vientos folclóricos que aportan, respectivamente, el mar y el campo gallegos. Donde en otros lugares resultaría impensable que una reiteración de sucesos luctuosos se convirtiese en tradición, en Galicia ha llegado a serlo -de un modo triste y romántico- que la gente muera en el mar (sin ir más lejos, en la fatídica Costa da Morte, con unos 60 navíos hundidos en el corto espacio de 100 años). De ahí que en la zona subsistan todavía las leyendas sobre sonidos extrańos que se confunden con el rumor de los océanos, como, por ejemplo, los de olas que, al oído de algunos, parecía que tocaban el piano, cuando no era el sonido de las teclas el que, inexplicablemente, parecía llegar a algunas personas desde mar adentro, según antiguos testimonios. No es de extrańar, por tanto, que Miguelanxo Prado se plantease la historia de una «viuda de vivos», tal y como 
se solía bromear con aquéllas que contraían matrimonio con un marino, a la hora de plantear De profundis, otro de los filmes que analizaremos.

Respecto a la tradición del campo, con sus brujas, sus curanderas y su Santa Compaña, la tradición oral, llena de magia y superstición, encuentra unos orígenes mucho más prosaicos, toda vez que los habitantes del mundo rural tendían, por ejemplo, a desconfiar de los médicos por entenderlos como figuras de autoridad que -dato crucial- además cobraban por sus servicios. Una extraña y distante relación con el resto del mundo, la de nuestros ancestros y sus secretísimos remedios para la salud, que perdura y subyace en el argumento de otra de las películas que trataremos, Brujerías, cuya propuesta abriga la nostalgia por ese mundo gradualmente engullido por el progreso.

La pobreza y el deseo de un mundo mejor, unidos al culto a los muertos, se hallan, por último, en el germen de la Santa Compaña, que aparece en El apóstol. En el caso de esta leyenda tan arraigada, la vocación de transmisión oral se pierde, prácticamente, en favor de su asunción casi automática como parte de la cultura en las zonas afectadas, a lo que se suma, entre sus componentes, la igualmente excelsa tradición musical gallega, profunda, variada y muy capaz, como sucedió en su día, de que reputadas figuras como Mike Oldfield, o el propio Philip Glass, quedaran sorprendidas al adentrarse en sus múltiples vericuetos.

Pero sirvan para definir, integradoramente, qué es exactamente una leyenda, y cómo se fueron transmitiendo en Galicia de forma escalonada, las aportaciones de Miravalles ${ }^{2}$, al señalar que aquélla es «un hecho real adornado o desfigurado, o simplemente desvirtuado por la tradición oral, que va modificando los detalles, no bien recordados, al pasar de boca en boca por generaciones sucesivas». El mismo autor detalla los intentos de clasificación de las leyendas gallegas a cargo de Vicente Risco y Carré Alvarellos, distinguiendo el primero entre leyendas etiológicas, históricas y hagiográficas, y clasificándolas el segundo por leyendas populares, religiosas, fantásticas y de encantamientos, históricas, y novelescas o caballerescas.

Sobre la construcción de estas creencias populares resultan también interesantes los exhaustivos estudios de Mariño Ferro, quien, por su parte, recuerda que (p. 169) «aínda que crentes e agnósticos defendan a súa existencia cunha fe inquebrantábel, en realidade as supersticións non existen. O concepto de superstición, que é moi antigo, desde o Século das Luces utilízase con profusión mesiánica, de maneira que vivimos o paradoxo de que a defensa da razón vai emparellada co convencemento de que gran parte da humanidade non sabe usala. Case ninguén comprende que as crenzas, incluida a crenza na superstición, teñen una función práctica, e poucos son conscientes de que o ser humano se caracteriza pola enorme capacidade de responder ás súas necesidades con múltiples solucións, adaptadas a espazos e tempos variábeis».

${ }^{2}$ Véase la interesante y didáctica clasificación en la siguiente dirección de la Bibllioteca Virtual Miguel de Cervantes: http://www.cervantesvirtual.com/obra-visor/el-ser-de-galicia-a-traves-de-sus-leyendas/html/. 
Esta función práctica de la superstición se explica, según Mariño, porque (p. 393) «Ningún costume ou crenza se mantén centos de anos sen cumprir ningunha misión», lo que automáticamente remite a la, también, inevitable influencia de la religión en la edificación primigenia de la riquísima imaginería fantástica y legendaria gallega (p. 394): «O catolicismo popular emprega un abundante e rico simbolismo de orixe medieval que hoxe resulta escuro incluso para a xerarquía católica. Pretender analiza-las crenzas campesiñas sen descifrar ese simbolismo é como intentar traducir un libro escrito nunha lingua descoñecida».

No es baladí la cuestión religiosa, toda vez que, a la hora de caracterizar el fundamento original de determinados personajes típicos del acervo galaico, como las «bruxas», algunas corrientes científicas han mantenido interminables disensos entre sí. Por ejemplo, Mariño sostiene que (p. 405) «a bruxería, en contra da opinión imposta polos antropológicos evolucionistas, non é un resto das crenzas pagás. Tódalas culturas, incluida a clásica grecolatina, cren na bruxería. A europea é, en canto concepción do Mal, parte integrante do sistema relixioso». Más aún: el autor eleva la propia brujería a categoría de «religión mítica del Mal» (p. 410): «Unha relixión mítica que invierte os ritos e principios morais cristiáns. Naturalmente, tamén inverte os lugares e os tempos para o culto. Para os aquelarres, o deus do Mal e as súas servas prefiren, como cabería esperar, lugares e tempos con alguna connotación maléfica».

Cuestión diferente sería ahondar en cada uno de los personajes integrantes del imaginario/bestiario popular, y en las diferencias entre ellos (de los trasnos a los mouros, pasando por biosbardos, diaños, nubeiros, etc.) $)^{3}$, cuyos estudios específicos, además, son innumerables. No vamos a abordar el tema en profundidad, aunque sí apuntaremos algunas pinceladas sobre los ejemplos que nos atañen, por las películas que vamos a estudiar. La Santa Compaña, referente de El apóstol y presente también, con sus propias variaciones, en Extremadura o Asturias, también recibe los nombres de Estadea, Antaruxada o "Visita», y consta como una procesión de ánimas que, según Fraga Liste, «cualquier persona que deambule por los caminos aldeanos, por las calles solitarias y poco iluminadas corre el riesgo de encontrar». Esta macabra procesión, derivada del lento proceso de conversión en maléficas de determinadas deidades paganas del norte de Europa, por la irrupción del cristianismo en el siglo IV, «es el anuncio de una muerte próxima de aquél que la encontrare. Los gatos espeluznan a su paso y los perros ladran aullidos. Se dice que la persona que la encuentra se queda atónita, momento aprovechado por los muertos para pasarle una cruz y desde ese momento, y acompañado por un perro que lleva una especie de cencerro, la esquila, está obligado a seguirlos». Cabe, sin embargo, según advierte el autor, una forma de escapar de la comitiva, en caso de encontrárnosla de madrugada: trazar un círculo en el suelo y meternos dentro, con lo que el desfile pasará de largo.

${ }^{3}$ Vale la pena revisar el pequeño glosario de criaturas mitológicas gallegas disponible en http://ekiria.org/cultura-sociedad-magica/historia-magicka/mitologia-gallega. 
De otro lado, en De profundis, que se adentra en las leyendas del mar, aparecen, entre otras situaciones y personajes legendarios, sirenas. Las sirenas han sido ampliamente representadas en distintas manifestaciones artísticas galaicas, desde las pinturas de Urbano Lugrís a pintorescos escudos heráldicos (la historia de los Mariño, una familia noble de Vilaxoan, se relaciona directamente, de hecho, con la leyenda de una sirena que no sabía hablar, pero que gritó el nombre de su hijo cuando vio que iba a ser sacrificado). A "A Maruxaina", la sirena más famosa de Galicia, le dedican, por su parte, una fiesta en San Cibrao (Lugo), aunque Miguelanxo Prado, como veremos, parece dotar al mito de una lectura distinta para su película, dentro de su caracterización como ente benevolente.

Antes de adentrarnos en el análisis de Brujerías, por último, conviene aclarar también que suele producirse confusión a la hora de distinguir entre la bruja y la meiga, y entre ambas con otra palabra derivada, meigallo. Sobre las dos primeras, la Guía da Galiza máxica, mítica e lendaria indica que (p. 86) «inda que, na práctica, ambos os dous vocábulos resulten sinónimos, semella que existe una certa tendencia a considerar as bruxas máis daniñas que as meigas». El meigallo, por su parte, sería aquel (p. 163) «bruxedo o feitizo que se apón ás meigas. As meigas botan o meigallo que consiste en que as persoas e os animais enferman, non medran e acumulan toda sorte de desgracias». En la historia gallega, la triste realidad ha dado pie a cantares como el que Celso Emilio Ferreiro dedicó a "María Soliña», la más célebre de las Brujas de Cangas, quien entró en las cárceles de la Inquisición en 1921, confesando, mediante suplicios, su condición de bruja, y siendo condenada más tarde a la confiscación de todos sus bienes.

\section{DENTRO DEL CINE GALLEGO}

Y ahí tiene usted -acabó el maldito arqueólogo, sonriendo como un Maquiavelo burlón- la prosaica, aunque melodramática verdad de la leyenda de la torre. Las pastoras dicen que doña Mafalda fue arrebatada por el demonio, que había tomado la figura de un gallardo doncel, y que el alma de la triste castellana, perdida de amores, se asoma de noche a esta ventana misma, exhalando ayes muy semejantes al ululante gemido del viento de la sierra... jYa lo creo! Como que no es el alma la que imita al viento, sino el mismo viento el que remeda el quejido del ánima condenada...

\section{La leyenda de la Torre (Emilia Pardo Bazán)}

En su Arte y técnica de la animación, Rodolfo Sáenz recuerda que (p. 51) «a menudo basta con tomar los mismos personajes de la serie y trasladarlos al interior de un clásico, para que esto provoque inmediatamente nuevas ideas. Solo habrá que hacerse preguntas; por ejemplo: ¿cómo reaccionaría nuestro personaje si se encontrara en un lugar habitado solo por gente pequeña? Si nuestro personaje está bien desarrollado, seguramente se comportará de manera muy distinta de Gulliver».

Pareciera que la frase se hubiese pronunciado a la hora de pergeñar películas tan distintas como las que van a ocuparnos, cuyo criterio de elección fue, amén de su diversidad técnica, el modo en que trasladan las leyendas y personajes descritos, 
dentro de una retórica elemental común y un riguroso respeto a las tradiciones. En ellas, los personajes originales se aprecian insertos «en el interior del clásico», como dice el autor (en este caso en los clásicos legendarios), dando lugar a un fresco revisionismo que, además, y pese a sus diferencias conceptuales y artísticas, cumple a la perfección, en los tres casos, con algunas de las reglas de la animación descritas igualmente por Sáenz: la primera, que (p. 337) «animar es representar una actuación mediante el movimiento; es cargarlo de emoción" (no sobra calidad en ninguno de los tres relatos, en este aspecto), y la segunda, relacionada con la impronta artística de los profesionales, que indica que (p. 337) «en el cine de animación, el personaje no es el actor, sino el animador, ya que es a través de su trabajo como se comunican las emociones, lo que constituye un logro difícil e individual».

Por si fuera poco, en todas las películas hay también espacio para una didáctica de la mitología galaica, que subyace tanto en el contenido como en las distintas formas cinematográficas que aparecen en cada historia, $y$, en menor medida, por la apelación a la curiosidad de la audiencia de la que hacen gala. Desgranemos brevemente, al fin, cada una de ellas:

\subsection{DE PROFUNDIS}

De profundis, de Miguelanxo Prado, es, con mucho, la película menos ortodoxa de las tres, por cuanto desaloja todo materialismo, literalidad o linealidad argumental, adentrándose, en su lugar, en un duermevela mucho más cercano a las sensaciones intangibles que brindan las (tristes) leyendas relacionadas con el mar de Galicia, y cuyo visionado causa la impresión de asistir a un relato compuesto por una sucesión de ecos lejanos, y ajenos a la normal comunión entre tiempo y espacio.

Con una apuesta decidida por la tecnología al servicio del arte (lo que vemos es una sucesión continua de óleos, técnicas mixtas, acuarelas e incluso dibujos a lápices de colores que conservan en cada fotograma la riqueza del trazo), Prado dio carta de naturaleza a una historia que concibió como un proceso interior, derivado de su infancia junto al océano, y a su «sospecha poética», como en alguna ocasión ha declarado, de que "alguna vez nos movimos por esas profundidades», sobre las que, además, confiesa haber tenido sueños inquietantes ${ }^{4}$.

De profundis también es un producto aventurado por carecer de vocación comercial; según Chelo Loureiro, el nivel de las técnicas 3D en el extranjero impedía competir con el mercado americano, por mucho que Continental, la compañía de la que Loureiro era productora ejecutiva, tuviese vocación internacional. Para entender el espíritu y las verdaderas intenciones de De profundis, tal vez resultan más esclarecedoras las palabras de Nani García, compositora de la música del filme, a quien la simple contemplación de los bocetos de Prado, dijo, lograba que la música «se produjera sola».

${ }^{4}$ Consúltese, sobre éstas y las siguientes declaraciones, el making of del DVD de De profundis. 
Como quiera que resulta complicado trazar un relato lineal de la película, describiremos, relacionalmente con la cuestión legendaria, el hilo conductor que parece guiar sus ensueños: para empezar, existe una casa en medio del mar, cuya torre alberga un estudio de pintura con motivos marinos. Cuadros en los que una sirena cohabita con grandes medusas, planos de un barco sobre una mesa, o un barco que se funde con un pez, y que comienzan a asentar la imaginería que nos espera.

Las siguientes escenas, arquetípicas, remiten a las tradiciones delimitadas por las «viudas de vivos», anteriormente citadas, y a la relación descrita entre música, ecos del mar y nostalgia del ser querido, sobre los que pivotará toda la obra: una mujer toca el violonchelo en el porche, frente a unas escaleras que bajan al agua, mientras que un barco de pescadores llega hasta ella y un hombre la saluda, agitando un farol, y pasando de largo. Grandes peces parecen bailar al son de su música. Ella sonríe; parece conectada con ellos.

A partir de aquí, las imágenes comienzan a perder el hilo conector con más frecuencia, redoblándose en su lugar los factores poético y retórico, sin descolgarse de las tragedias marinas: por ejemplo, en el barco un niño canta y deposita la luz de sus notas luminosas en las manos de quien parece ser su padre. Con ella los pescadores hacen los cebos que tiran al mar. Sobre una roca muy elevada, junto a un faro, un viejo ciego hace volar una cometa con forma de pez. Pero, de repente, nubes negras tapan el cielo junto al faro. Se desata la tormenta y una gran ola hunde el barco, que queda encajado en el saliente de un acantilado submarino. La mujer, en casa, se siente destrozada. Al poco, el hombre despierta bajo el agua y mira a su alrededor, momento en que comienzan las auténticas maravillas, engarzadas en la nostalgia y el puro romanticismo: procesiones de ballenas, una sirena (o un xacio, según la mitología gallega), que le acompañará a partir de ahora, y un viaje lisérgico que comienza, tras tocar a una medusa gigante, en el que se cruzan bocetos y dibujos con las maravillas vivas del océano.

Tras una serie de escenas que implican morenas y sirenas con torso masculino, el hombre se deja caer durante un sueño a una fosa abisal, en la que cohabita con gigantescos peces y criaturas del abismo; la sirena, mientras tanto, escucha gritos, se asoma al abismo y ayuda al marinero, haciendo que guarde silencio y cierre los ojos: una nueva metáfora, del amor en esta ocasión.

Bajo el agua, la pareja visita una ciudad submarina, muy similar a cualquier pueblo español con raíces antiguas, por la que él se interesa. Más tarde, su compañera lo conduce a un santuario antiguo, por una abertura oscura que lleva a un cementerio de barcos. Ella quiere salir de ahí inmediatamente (como si su yo «real», la mujer que en la casa sueña con ser la sirena, rechazase esta perenne amenaza de la muerte), pero él no quiere. Ella lo besa entonces y se miran profundamente a los ojos. Vemos a la mujer tocar el violonchelo en la superficie, y a él en unas fotografías con todos los recuerdos de la pareja, que ella porta, en una sucesión de recuerdos del joven marino: él pintó los cuadros que decoran la casa y los sueños de ella, que llora ante las fotos. Se echan de menos con el alma, con lo que el hombre termina rechazando el amor de la sirena.

Al poco, nadando entre los barcos, el joven encuentra el que, mitad pez, aparecía en los planos sin terminar de su casa. Se pone al timón y, merced a una 
extraña magia que ni siquiera él comprende, lo saca a la superficie. Al tiempo, la mujer en casa lee, recostada contra el árbol del jardín, los planos del barco-pez en una libreta. Los peces más grandes escoltan al barco en su reflote. Viajan al acantilado donde quedó el pesquero, del que parecen deprenderse mariposas de luz, como las que salían de la boca del niño, y que salen a la superficie.

El barco emerge también al fin. La mujer mira hacia afuera, como si hubiera estado esperándolo o invocando su vuelta con su música. Por la noche, se asoma con sorpresa. El barco, bajo el agua, se ha convertido en un gran pez rosa con la marca de la sirena en su cuello. Ella lo contempla con sorpresa primero, y con una sonrisa cómplice después, como si intuyera su participación en el proceso, a través del amor, el recuerdo y el ensueño. Definitivamente, la pérdida y la distancia no se han superado, pero se ha completado una suerte de transformación que parece ofrecer cierta esperanza.

\subsection{BRUJERIAAS (MEIGALLOS)}

Es revelador que el primer plano de Brujerías (Meigallos) muestre un ejemplar de Merlín e familia, de Âlvaro Cunqueiro. El libro se halla entre las pertenencias de la abuela de Malva, la protagonista, cuyas andanzas la van a situar en la frontera entre leyenda y modernidad, entre brujería y tecnología, a propósito de la tradición curandera de sus mayores. Ello se refleja en cómo, al principio, a la niña no le gustan las pociones, aunque roba un recipiente que contiene un compuesto para volar. Su abuela, Lalilas, que efectivamente es curandera y capaz, por ejemplo, de sanar el dolor de una anciana o de hacer volar a un caracol gracias a sus preparados, la previene de que hay personas que buscan quitarle sus pócimas, que en malas manos serían muy peligrosas, y le explica también que la magia está en todo, no solo en los amuletos (a lo que Malva responderá que también su móvil es mágico). «Conservar la tradición es complicado. Ojalá todo se resolviera apretando un botón», le explica la mujer.

Los antagonistas reflejan, por su parte, la crítica que la cinta realiza al exceso tecnológico actual: agentes con gafas de sol, intercomunicadores, e incluso un pequeño dron que los espía con su minicámara. Cuando los sicarios, por ejemplo, se desprenden de su comunicador, entran en un estado de somnolencia y desorientación, mientras que, cuando lo llevan, actúan como zombis. Tras indicarnos que ambas se hallan en una feria das menciñeiras (curanderas), Malva está dispuesta a volar a cualquier precio (su amigo Selu lo hace en parapente), aunque la vemos desechar una escoba (precisamente por tratarse de algo antiguo, de una "cosa de brujas» hacia la que la chica siente la habitual aversión adolescente), eligiendo, en su lugar, un paraguas, que rocía con la poción obtenida al principio, $\mathrm{y}$ al que aplica un conjuro.

Como podría esperarse de los citados antagonistas encastrados en la modernidad, al poco Lalilas es secuestrada por los magnates de una empresa comandada por la malvada Rufa, quien se muestra dispuesta a quitarle sus recetas y pócimas, principalmente el recipiente que hace volar. Las instalaciones se hallan en una zona 
natural protegida difícil de rastrear, por lo que, a la larga, Malva lamentará no haber aprendido del origen rural de su abuela.

Sin embargo, es gracias a un signo gestual tradicional que la mujer le enseñó como Malva encontrará una entrada secreta a la fábrica de Rufa. Un policía, personaje secundario, sigue, por su parte, a la nińa, accediendo temporalmente a un mundo inspirado por la tradición gallega en el que las flores tienen las propiedades mágicas e inteligentes que les conceden a las pócimas de la abuela, mundo que, además, es descubierto a través de la declamación de unos versos.

Distintas peripecias conducen a un enfrentamiento, cerca del final, en el que caben declaraciones de intenciones como las de Rufa, quien exclama, tras creerse en poder de la fórmula para volar, que "la tecnología es el futuro", a lo que Lalilas responde que «la tecnología y la naturaleza deben encajar juntas».

Finalmente, son de nuevo los gestos tradicionales de las manos de su abuela los que comunican a Malva que eche resina al preparado que la han obligado a hacer, y que, al aplicarlo a los zapatos de sus enemigos, los deja pegados al suelo. Malva pide a Lalilas aprender todo lo posible a partir de ese momento, y, cuando, en su huida, Rufa llama «brujas» a las dos mujeres, ellas lo niegan: «Brujas no: curanderas», contestan. En los instantes finales, Malva termina integrándose en el club de voladores (parapente) de su amigo Selu, despidiendo la película con la conocida cantiga gallega infantil dedicada al «arroz con chícharo».

Según Virginia Curiá, Brujerías tuvo hasta nueve versiones de guion, todo para conceder ese halo de modernidad «a las meigas gallegas (curanderas), a las que durante siglos se las tuvo como brujas, mientras que su labor era ser conocedoras de la medicina tradicional, utilizando plantas y remedios naturales para ayudar a sus vecinos ${ }^{5}$. Pese a contar con escasos medios de realización y distribución, la directora, como puede apreciarse durante el visionado, sí tuvo en mente a sus grandes referentes: «La influencia principal para nosotros es el cine de Hayao Miyazaki, el tratamiento que hace de sus personajes y la humanidad de la que los dota. Nos gustaría mucho acercarnos, aunque fuera lejanamente, a su forma de contar historias». Con todo, en la película prima la voluntad de recuperar, desde una perspectiva educativa y para la posteridad, el papel de las brujas de cara al mundo infantil, aunando las antiguas funciones de la superstición como medio de control social y como explicación de determinados azares, con el materialismo tecnológico que, hoy en día, sume a la infancia en la "cultura de la literalidad" tan típica, para sus detractores, de los tiempos modernos.

\footnotetext{
5 Véanse sus declaraciones completas en esta entrevista para la revista digital Filmarte: http://www.filmarte.net/Entrevistas/virginia-curia-brujerias.
} 
Por último, El apóstol, considerado «el último filme maldito del cine espanól $»^{6}$, es la obra más hollywoodiense de las tres. Su manufactura de impecable stop motion (es la primera película europea con este formato desarrollada mediante producción estereoscópica), sus más de cinco millones de euros de presupuesto, y su reconocimiento en festivales internacionales están a la altura de la particular transmisión del mito de la Santa Compaña al que la película se rinde en su relato. Con figuras creadas a partir de los grandes actores que les pusieron voz (de Luis Tosar a Paul Naschy, pasando por Geraldine Chaplin), a grandes rasgos, El apóstol cuenta la historia de Ramón, un preso fugado que en su huida es desviado hacia Xanaz, un pueblo cercano al camino de Santiago, sobre el que pesa una maldición terrible. La caracterización de los aldeanos y el cromatismo de la cinta, que recuerdan al tremendismo del arte y las crónicas de la denominada "España negra», se mezclan con otros referentes como el de don Cesáreo, párroco del pueblo y principal antagonista, quien claramente podría resultar un trasunto de Nosferatu (F.W. Murnau, 1922). Otros vecinos de Xanaz presentan propiedades animalescas, o remiten, por su parte, a figuras frankensteinianas o similares al zombi clásico. El secretismo, el costumbrismo férreo, las raíces católicas, los ecos de animales en los bosques y las edificaciones tristes y ruinosas construyen, en un conjunto excelentemente amalgamado, un canto a las leyendas más oscuras del paisaje galaico, y dominan la ambientación de la cinta, mucho antes, incluso, de que la Santa Compańa haga acto de aparición durante la historia.

En este sentido, el respeto a los parámetros de esta leyenda también es total: al poco de que Ramón trate de aprovecharse de los aldeanos para robar unas joyas, éstos a su vez lo drogan y engañan, y termina sosteniendo la cruz de la Santa Compaña. Sarustiano Briones, su anterior portador, le explicará que, efectivamente, se trata de una procesión de almas en pena que vaga por los caminos de Galicia buscando las de aquéllos que han muerto, para expiar sus pecados. Es una mensajera de la muerte, advierte, peligrosa en principio solo para aquéllos a los que les ha llegado su hora, pero también para los vivos que se la encuentran y que no son capaces de protegerse, por cuanto quedan condenados a acompañarla en su funerario viaje nocturno. Briones indica a Ramón, además, que dispone de tres noches para pasarle la cruz a otra persona viva, so pena de empezar a debilitarse hasta morir.

En sus indagaciones diurnas posteriores, Ramón descubre que Xanaz quedó maldita al acabar entre todos sus habitantes con la vida de un peregrino enfermo de peste negra, durante la Edad Media. Un muy elaborado pasaje musical explica que el pueblo sufrió la plaga durante tres meses, y que de algún modo Cesáreo, que ya vivía entonces, contactó con el diablo para salvar la aldea. Se sugiere igualmente

${ }^{6}$ Sus terribles problemas de distribución, tan recalcitrantes que algunos intuyeron como cosa de meigas, se explicitan a la perfección en este artículo de la revista Fotogramas: http://www. fotogramas.es/Noticias-cine/O-Apostolo-el-ultimo-film-maldito-del-cine-espanol. 
que esa "caída al infierno" eleva a las almas en pena de la Santa y las dirige hacia el pueblo, donde sus habitantes quedaron en un estado permanente de muerte en vida, consumiendo con el tiempo todos los recursos de los alrededores, y viéndose obligados, como se observa al principio, a desviar a los peregrinos de Santiago hacia sus muros, para ofrecerlos en sacrificio y engańar así a la comitiva, que insiste siempre en regresar para saldar su deuda con los nativos.

La visita del antipático arcipreste de Compostela servirá, hacia el final del filme, como excusa para pasarle a él la cruz y romper la maldición mediante una estrella pintada en el suelo (no un círculo, en este caso), en el que al principio se protegen Ramón, el propio arcipreste y Pablo, su ayudante, de modo que la Compaña, al no encontrar a nadie a quien llevarse, termina localizando a don Cesáreo $\mathrm{y}$ al resto de aldeanos. Una vez rota la maldición, incluso los colores del filme, que como decimos habían venido remitiendo, entre otras cosas, al cine silente, y que habían dominado la ambientación hasta entonces, desaparecen, dando paso a una realidad nueva y breve, pero de corte mucho más cercano y naturalista.

\section{CONCLUSIONES}

En una época a caballo entre dos culturas, y dado que el auge de la animación gallega fue un sueño al que las circunstancias pusieron fecha de caducidad, probablemente las películas de esta etapa no sean las mejores transmisoras de la amplia tradición legendaria de esta comunidad, pero sí son, por el momento, sus últimos testigos fiables. Como se ha dicho, Urxa y Siempe Xonxa incluían trazas de las leyendas gallegas, pero fue el cine de animación el que contribuyó, con decisión y escasos complejos, a comunicar, a las generaciones venideras, la riqueza de la tradición legendaria oral y escrita de los pueblos de Galicia.

Por otro lado, pese a la vocación internacionalista de alguna de las películas descritas, ninguna de las tres buscó, en sus orígenes, un mercado amplio: en $E l$ apóstol se barajaron otros temas antes de su concepción, y no había intención manifiesta, en un principio, de ceñirse a la leyenda de la Santa Compaña; el medio de vida de Virginia Curiá, pese a ser una apasionada del cine de animación, en realidad siempre ha sido el mundo publicitario, y las disquisiciones poéticas de Miguelanxo Prado, en De profundis, fueron el resultado, como hemos dicho, de un proyecto muy personal.

Nunca hubo, pues, en estas películas, más vocación de «ser comprendidas» fuera de las fronteras de Galicia, ni de mayor expansión cultural, que la de manifestar un profundo amor a la tierra y a la cultura propias, mediante la estimulación en el espectador del interés por tan amplísimo acervo. Si todas ellas lo consiguen, a la hora de la verdad, tal vez dependa de los ojos del espectador; ahora bien, en todas bulle el sano prurito de refrescar las antiguas narrativas galaicas, bien mediante el guion, bien mediante la técnica, y de modernizar, en general, los viejos cantos seculares. Todo ello a pesar del respeto que, igualmente, se muestra en los tres casos por la férrea raigambre de las historias y leyendas mil veces transmitidas oralmente por quienes las creyeron de verdad en tiempos remotos; los susurros y las formas fan- 
tásticas de tantas criaturas imaginarias del campo y de la mar (tanto de las que pertenecen a la luz como de las que fueran -siguen siendo- patrimonio de la oscuridad), $y$, en fin, de las palabras, sonidos y sensaciones que, en su conjunto y a través de los siglos, han concedido a Galicia una identidad única, dentro y fuera del territorio nacional.

Recibido: febrero de 2019. Aceptado: mayo de 2019 


\section{BIBLIOGRAFÍA}

Fraga Liste, E. (1989): «Costumbres heterodoxas en Galicia», Revista de la Asociación Europea de Profesores de Español (AEPE), 36-37, 189-196.

Mariño Ferro, X.R. (2007): Manuela Branco Romasanta, o lobishome asasino, Vigo, Edicións Nigratrea, S.L.

Mariño Ferro, X.R. (2000): Antropoloxía de Galicia, Vigo, Edicións Xerais de Galicia.

VV. AA. (1998): Guía da Galiza máxica, mitica e lendaria, Vigo, Editorial Galaxia.

Cuba, X.R., Miranda, X., y Reigosa, A (1999): Diccionario dos seres míticos gallegos, Vigo, Edicións Xerais de Galicia.

Loureiro, C. y González, X.M. (2000): Galicia. Antropoloxía, A Coruña, Hércules de ediciones, SA.

Sáenz Valiente, R. (2008): Arte y Técnica de la animación. Clásica, corpórea, computada, para juegos o interactiva, Buenos Aires, Ediciones de la Flor.

\section{AGRADECIMIENTO}

Es justo reconocer la contribución, para la elaboración de este artículo, de Fortunato Rodríguez Fernández, profesor de Animación en Entornos Audiovisuales y Multimedia de la Facultade de Ciencias Sociais e da Comunicación de la Universidad de Vigo, quien amablemente se dejó entrevistar por el autor de este texto para configurar los dos primeros epígrafes del mismo. 